\title{
What happened to post-cognitive psychology?
}

\section{Hedwig te Molder}

Wageningen University (Strategic Communication Group) \& Twente University (Department of Philosophy)

The Netherlands

Email hedwig.temolder@wur.nl

In C. Tileaga \& E. Stokoe (2016) (Eds.), Discursive psychology: classic and contemporary issues (pp. 87-100). Abingdon, UK: Routledge. 
Chapter 6

What happened to post-cognitive psychology?

Hedwig te Molder

Target article: Potter, J. (2000) 'Post-cognitive psychology', Theory \& Psychology, 10: 31-37.

It is fifteen years since Jonathan Potter (2000: 31) declared that now was "an occasion for risking big thoughts about what comes next". He was referring to the future of a psychology outside the cognitivist paradigm. Derek Edwards' Discourse and Cognition (1997) had been published a few years before. The time was ripe for the development of a full-blown alternative to the cognitivist perspective that had been dominating psychology since it parted from behaviourism.

As is clear from the contents of Potter's manifesto - and the fact that the article was published in Theory \& Psychology - his appeal was predominantly directed at psychologists (and psychologists in the making). Even though that was the case, the post-cognitive project never became part of mainstream psychology. More than anything else, it sparked discussion and critical selfexamination among interaction analysts. This chapter focuses on the actual and 
potential implications of post-cognitive thought for interaction analysis, and does so in two ways.

Firstly, on a more abstract level, I will re-examine the discussion on cognition that is reflected by the collection of papers in Conversation and Cognition (te Molder \& Potter 2005). Despite its apparent non-cognitivist character, conversation analysis (CA) occasionally shows signs of nostalgia: it is longing for a world in which cognition represents firm ground and real evidence. Discursive Psychology (DP), on the other hand, consistently treats cognition as a participant's achievement, and a practical resource in interaction. This makes it more radical from a philosophy of science point of view, and for some, though unjustly, more conservative in terms of the extent to which the approach is truly interactional.

Secondly, I will discuss an emerging subfield in CA - epistemics-in-action - and review some of its achievements in the light of post-cognitivist criteria. While the field bears a strong resemblance with some of the long-standing key ambitions of Discursive Psychology (DP), there is little or no uptake of earlier insights from DP. I want to argue that cross-fertilization between CA and DP is essential here. It can prevent epistemics from slipping into a more traditional understanding of knowledge before the benefits of a post-cognitivist approach have been reaped. 


\section{Conversation and cognition}

What is post-cognitivism? The core is perhaps most elegantly formulated by Harvey Sacks, founder of CA, when he reassures analysts about the kind of concerns they need not have:

Don't worry about how fast they're 'thinking'. First of all, don't worry about whether they're thinking. Just try to come to terms with how it is that the thing comes off. Because you'll find that they can do these things. (...) Look to see how it is that persons go about producing what they do produce.

(Sacks 1992: 11)

Sacks's key advice is to focus is on practices - how do participants go about producing what they do produce - rather than on processes under the skull. Note how he presents this focus as methodological rather than ideological. Trust participants' skillfulness and take their abilities for granted; only then researchers will be able to decipher how participants do it. It is not necessary to assume that cognition does not exist, or define it as a no-go area. It should be put between brackets, by way of methodology, in order to be able to recognize and analyse participants' practices. There is no "neat Chomskian realm of underlying processes and entities" (Potter 2000: 36) to rely on; instead the researcher must content himself with the ostensibly messy but "rich surface of language" (Edwards, 2006a: 41).

The focus on natural conversation has major implications for how one understands human behaviour. One of the defining features of a traditional cognitive worldview is the idea that mental states precede people's talk and behaviour. Behaviour can be explained in terms of motives, intentions, beliefs, et cetera that drive, cause and predict that behaviour. While not all cognitivist 
studies claim cause-and-effect relationships, they nonetheless carry the aura of causality and explanatory power, and the corresponding promises of prediction and applicability. The aim or suggestion of causal explanation is a crucial difference with the framework of normative accountability that underlies CA and DP (Edwards 2012). Behaviour is not understood 'from the outside', as driven by mental predicates, but 'from within', by looking at how people understand each other. People do and define actions against a background of what is normal and proper. But norms and rules are not simply obeyed; they can be made relevant and thus also constitute the situation as understandable in a particular way.

\section{The 'usefulness' of cognition versus interaction}

In a way Sacks's post-cognitivist notion of human action makes things a lot easier. As an analyst you no longer have to worry about whether people think, let alone how fast they think. You can take all that for granted and leave it where it is. However, there is no sense of relief in most cases. The lack of causality is often framed as a methodological inadequacy (cf. Edwards, 2006). It is not seen as a choice for a perspective that neatly fits the requirements of the object of study. It is positioned as having no firm ground, no Reality to start from ('this is how people really think'; 'this is how it really is'). As a consequence, a post-cognitive framework is more easily framed in terms of what it lacks or cannot do than in terms of what it can do. It functions as a second-best alternative, waiting for real evidence to come. Interestingly, some of these sentiments can also be found among interaction analysts themselves.

Judging from Sacks's quote, one would think that (a form of) non-cognitivism would be a matter of course among conversation analysts. However, from the 
collection of papers in Conversation and Cognition (te Molder \& Potter, 2005) a different picture arises. Originally, the volume was meant to set up a postcognitive project in the broadest sense of the word. Leading conversation and interaction analysts were invited to examine and theorize on the status of cognition in interaction. Its aim was to further flesh out the post-cognitive perspective that we, Jonathan Potter and I, thought that CA (already) was, and to make it more widely known, i.e. outside the relatively small circle of CA scholars. The volume ended up full of sophisticated studies but it was much less agreeing about the role of cognition in interaction than we had expected. Simplifying to some extent, three sorts of conceptualizations of cognition in relation to interaction can be found in the book:

(1) According to some contributors cognitive aspects can and must be distinguished from interactional features. Robert Sanders, for example, proposes to ground and justify, or challenge, the observational claims that are made in discourse studies by testing the assumptions on cognition on which they rest, thereby arguing against Sacks's advice not to worry about people's capacities to think fast. Paul Drew recognizes cognitive moments in the interaction - for example: the intention to decline an invitation, or a state of confusion - which allow the analyst to establish the actual mental state of an interactant (for a thorough discussion of Drew's contribution, see Potter 2006). Anita Pomerantz argues that it is possible and useful to let participants, who were part of an interactional study, share their views of what actually happened with the researcher in the form of video-stimulated comments. She suggests that CA is already more cognitivist than it thinks it is. In this sense, her method would only 
make explicit what is already assumed or hinted at in CA work. The similarity between these different reasons for distinguishing between cognitive and interactional features within the analysis, is the assumption that (only) with the help of cognition it is possible to establish participants' real understandings (Pomerantz), actual intentions or confusions (Drew), or to test whether participants' competencies actually match the assumptions on cognition on which interaction studies rest (Sanders). In short, the complementarity of a cognitive to an interactional framework consists of its capacity to provide proof that otherwise would not be available. However, this move reflexively marks the interactional results as not providing the necessary (extra) substantiation, as if the studies cannot stand on their own feet even when the goal of the analysis is different, namely shedding light on the normative organization of the talk.

(2) A second set of scholars develops an agnostic view of cognition on the basis that it is hard to establish whether or when we deal with 'real' motives, intentions, attitudes et cetera. We should therefore not jump to conclusions when it comes to analyzing cognitions. John Heritage's chapter is an example of this. It focuses on how the particle 'Oh' is used to display remembering, or not having expected a particular answer to a question, and how it is bound up with knowledge entitlement issues. Heritage's proposal is to prioritize and prefer an interactional approach to the change of state token 'Oh', over a cognitive view of it. There may be a relationship between the cognition and the display of that mental state in interaction but we cannot be certain, for example because cognitive states 
may be withheld. We must refrain from making statements about cognition when we lack the evidence, and that is usually the case. Robert Hopper's analysis of a corpus of calls made from and to President Johnson's office soon after he became president of the US, is a thorough examination of possible evidence for the existence of so-called prestrategies in talk. He concludes, very similar to Heritage, that mental states of this kind are very hard to pin down, which should make analysts reluctant to draw conclusions of a cognitive nature. Contributions from this perspective suggest that a cognitive 'check' or embedding of what can be discerned interactionally, could be important but unfortunately there is no(t enough) evidence on which to base these claims. What they do not make clear however, is why a cognitive element would be necessary and/or what it adds to the existing interaction analysis.

(3) Thirdly, there is the discursive psychological view of cognition, as represented by the chapter from Derek Edwards and Jonathan Potter. While it propagates an agnostic stance regarding cognition, it does not do so out of a lack of possible evidence. Here, cognition is put between brackets, not because it is declared non-existent or it cannot be proven, but because it is most fruitfully seen as a participants' resource pur sang. Interaction is an area on its own that warrants investigation, and for this area to become researchable, one has to 'methodically' ignore the cognitive realm. Edwards (1997: 99) points out that "conversational exchange is the area in which motives and intentional states are at stake for participants, and is therefore analytically prior to the mental states that supposedly precede it". In this respect, the DP view on cognition 
remains closest to the perspective that Harvey Sacks originally seems to have developed: do not worry about cognition, but let it sit where it sits.

\section{DP as the radical version of post-cognitivism}

Without it ever having been its objective - on the contrary - the volume on Conversation and Cognition shows the unease of conversation analysts when confronted with the role of cognition in and for interaction analysis. The argument for a (partly) cognitive approach is predominantly based on 'negative' reasons: what do we miss when we leave out cognition? This question anticipates on that we would miss a lot, most likely real proof for what we conclude on the basis of our interactional analyses. My argument is not that the question about what we would miss is an unjustified one. Its focus is however too narrow. We must also wonder, and ponder a bit more about what exactly we gain by focusing on (what seem to be) surface matters, at the expense of diving into the (again seemingly) deep waters of cognition. Though perhaps cognition can be 'done', we do not need it to show the robustness of our studies that focus on a different terrain - a terrain for which the chosen methods seem highly appropriate. This is difficult for a perspective that, despite its achievements, has always remained somewhat marginal. But its unique focus and systematic nature of inquiry is also the main and the best reason for its attractiveness.

In line with its post-cognitivist nature and aim, DP has always resisted the inclination to draw a line and define a place that is beyond interactional scrutiny (cf. Edwards, Ashmore \& Potter 1995). This is best expressed in its interest in the mind/world, or subject/object, distinction (Edwards \& Potter 1992; Edwards 1997) as a participants' rather than an analyst's topic. Precisely where we seem 
to bump into a domain that should be reserved to the researcher, namely the distinction between reality and subjectivity or cognition itself, discursive psychologists become truly interested and turn it into a participants' matter. Cognition is consistently dealt with practically, that is, as something managed in talk, up to the point that the distinction between cognition and reality itself is at stake for participants. Rather than this being a unique situation, it is common practice in everyday talk. The DP interest is there because it concerns an essential part of what people do in their talk, if not unavoidable and omnipresent. Rather than presupposing a particular boundary between the objective world and the subjective mind, talk is studied for how participants draw the line themselves, and the kind of interactional business that it performs. In the early days of DP, the interest was particularly in how things and events come to be established as factual and objective. Bound up with this interest, there was a focus on how stake and interest are managed by speakersconfessed, countered, or treated as irrelevant-so as to protect the factuality of their descriptions, or, conversely, how speakers attribute them to others in order to undermine an account's objectivity (Potter, 1996). Displays of ignorance ('I don't know') can be drawn upon as to play down the speaker's stake in a particular description, in this case speaker Jimmy's proneness to see his wife's 'sociability' as revealing 'sexual availability':

7 Jimmy: $\quad$ Connie had a short skirt on I don't know

(Potter, 1996: 131, DE-JF:C2:S1:10 - emphasis added) 
Precisely at the point where Jimmy could be accused of jealously inspecting the length of his wife's skirt, he displays uncertainty about it, thereby resisting the implication of him being biased about his partner's intentions.

More recently, the idea of stake management has been extended to cover the idea of managing one's 'subjective side' more broadly (Edwards 2007).

Subjectivity management refers to warding off stake or prejudice but also to resisting the idea that speakers exaggerate what they see or that they are disposed to be negative. Furthermore, the 'subjective side' is not by definition a threat to objectivity. Interactants may for example display themselves as an honest person or as someone with an inclination to speak plainly, and thereby enhance the objectivity of what they say.

In a study on modal expressions in police interrogation - as in: 'I wouldn't hurt an old lady' -, Edwards (2006b: 479) shows how suspects use the inferential qualities of 'would' so as to build the subject-side basis of their account:

(1) PW:1:15 (Edwards 2006: 479), $\mathrm{S}=$ suspect ; $\mathrm{P}=$ police officer

\begin{tabular}{|c|c|c|}
\hline 13 & S: & I didn' push \\
\hline 14 & & the woman or nothin, (0.5) I really did not do \\
\hline 15 & $\rightarrow$ & that $=$ I'm not that type of person $y^{\prime}$ know what I \\
\hline 16 & & me:an. .h Fair enough I stole the ciggies, (0.9) \\
\hline 17 & $\rightarrow$ & I wouldn' hurt an old lady. \\
\hline 18 & & $(0.5)$ \\
\hline 19 & P: & [Right. ] \\
\hline 20 & S: & [ No. ] (.) Not a chance.= \\
\hline
\end{tabular}

The 'would' in the suspect's self-assessment (line 17) invokes both generalized normative and (counter-)dispositional knowledge. As recipients we are invited to place ourselves prior to the event described and conclude that the suspect has not done what he is accused of: he recognizes the current moral order - you 
should not hit elderly ladies- and he is the type of person that would never do such a thing.

Rather than denying head-on, the speaker draws on what Edwards calls the backdated predictability of 'would' to manage his subjective side and provide him with the much-needed accountability. Note how the police officer is minimally acknowledging, but not objecting to, the suspect's generalized normative claim (line 19). The police officer's routine orientation to pursuing factual evidence tends to exclude such claims and thereby allows the suspect to produce a robust moral self-assessment.

Sneijder and te Molder (2005) showed how a similar blend of logic and morality was drawn upon in an online forum for vegans. A modal expression embedded in a script formulation, enabled participants to attribute responsibility for vitamin deficiencies to individual practitioners, rather than to veganism as a whole. As with the backdated predictability of 'would', it was the formulation's design as a factual prediction, and the hidden normativity of the modal construction therein, that permitted speakers to display their attributional work as unmotivated:

(Sneijder \& te Molder 2005: 685-686) Date: May 05

From: Paul

10 You can buy vegan B12 pills under

11 the Solgar brand, but check that

12 suitable for vegans is written on

13 the jar. I use the $100 \mathrm{mg}$. tablets

14 which I buy from the health food

15 store. You can get D3 by being

$16 \rightarrow$ outside regularly. (sunlight). By

$17 \rightarrow$ just ensuring you have a varied

$18 \rightarrow$ diet you won't easily run the risk

$19 \rightarrow$ of any other vitamin deficiency.

In lines 16-19, Paul presents a varied diet as a condition for not risking vitamin 
deficiency, using a scripted formulation (By doing X, you will not Y). 'Risking vitamin deficiency' is reformulated into a logical consequence of individual behaviour rather than something that is inherent in veganism. Note how the future orientation of won't easily (line 18) is difficult to distinguish from its reference to the recipient's ability to perform the required action. The suggestion is that 'not running the risk of vitamin deficiency' will (almost) directly follow from ensuring a varied diet. This expectation, however, also attends to the ability and therefore the rational obligation of the recipient to prevent deficiencies by following the proposed guidelines. The rationality of this and similar constructions allowed speakers to project themselves as 'doing description' rather than managing self-interest. It can be heard as an attribution of responsibility or blame, while it avoids associations with the need to disguise ideological weakness or to protect one's lifestyle against threats from outside. As with the modal expression in the police interrogation, this script-and-modalconstruction appeared robust, as it was not pursued or objected to as long as its potentially blaming character could plausibly be denied. It could be seen from the one case in which the formulation attributed blame in a more explicit manner, and evoked a defensive uptake, that its routinely descriptive character was important for the interactional business performed (ibid.: 689-692).

\section{From subjectivity management to epistemics-in-action: on rules to follow or rules to use}

Discursive psychological research has always been interested in the factinterest-accountability triangle, that is, in the interplay between mind and world, or subjectivity and objectivity, as seen through the eyes of participants 
themselves, and in how reports, while handling these matters, attend to the speaker's own accountability (Edwards \& Potter 1992). The interest is not limited to what is achieved with managing that interplay but extends to how exactly speakers handle the subject-side basis of what they say (Edwards 2007) and what members' objectification methods (Potter 1996) consist of. A discursive psychologist is interested in that the action is performed but also what is being done to perform it. For example, speakers may underline the spontaneity of their observations, i.e. present them as not in any sense mentally prepared, as to ward off potential accusations of prejudice (Edwards 2003). This focus on action is sometimes mistaken as a focus on content per se. Stivers, Mondada and Steensig (2011: 7-8) distinguish two strands of research that address "how knowledge is managed in and through social interaction". The first strand is discursive psychology, focusing on "how knowledge, cognition, the mind and other psychological constructs are dealt with as topics by participants in interaction". The second strand is mainly represented by conversation analysts, as Stivers et al. point out, and "has not focused on the content on what is said but on epistemic positions taken through language and embodied action" (my emphasis). Discursive psychology is thus defined as focusing on content rather than epistemic positioning. While it is not entirely clear what the latter is referring at, it seems to reduce DP to a kind of content analysis that is stripped of its interactional context. Although no hard and fast rule, DP studies usually want to create an interaction-based pathway into a relevant domain rather than transcend that particular domain per se and reveal universal language structures. While the first does not exclude an interest in the second, the practical consequence of such an entry point may be that there is a specific 
interest in what the actions performed precisely entail, and the implications thereof for the field that is studied.

A study of face-to-face meetings between scientific experts and celiac patients about a new gluten-neutralizing pill (Veen, te Molder et al. 2012), showed how a particular question design regarding the use of the pill suggested primary access to the patient's life by the experts and the irrationality of the person who would refuse the pill. On the basis of this study, recommendations were formulated on how to best interact with patient-users in relation to new therapies in the field of celiac disease. An example from a different domain is Wiggins' (2014) study of family mealtime talk. It demonstrated that the parents typically claimed epistemic primacy over their children's food preferences. The children's claims about 'likes' and (especially) 'don't likes', on the other hand, were frequently countered by their parents or treated as inappropriate. Wiggins concluded that it could be more effective for parents to inquire about, or soften claims about, their child's food preferences, so as to enable the children to claim epistemic primacy over their bodily states.

The crucial aspect to note here is not that the DP approach is distinctly different from CA. There is no question of a difference by principle between CA and DP - they cherish the very same interactional outlook on talk. DP, however, has always had a simultaneous interest in conversational normativity as found in adjacency pairs, that is, the relevance of (or preference for) a second pair part (e.g. an answer) as set up by the first pair part (a question), and the normativity of everyday social rules (such as what it is to be a credible expert or a good parent, including their rights and responsibilities).

In the case of the previously mentioned expert questions about the celiac 
pill, for example, both the conversational normativity is of importance - as the questions were designed to prefer particular answers - and the orientation to rules about what a rational patient or a good expert is (Veen, te Molder et al. 2012). The following fragment is taken from one of the patient meetings organized by the Celiac Disease Consortium, a Dutch innovation cluster consisting of representatives of scientific research, patient associations, dieticians, general practitioners and industry. The closed questions that were used by the scientific experts (Ex) to ask patients (P) about a pill they were developing, biased the patient's reply to assuming the pill's use, and accepting the presuppositions that were made in the preface regarding the patients' quality of life (problematic) and the safety of the pill (100\%):

\section{Group 1, 24:26-26:20}

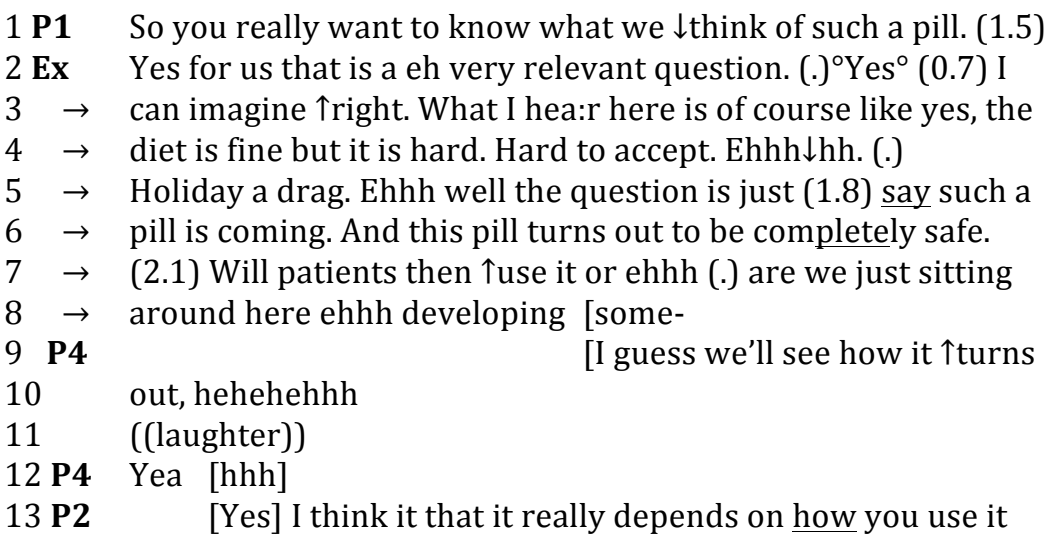

The patient's turn in line 1 establishes what patients ' think of such a pill' as a new topic on the agenda. While acknowledging the relevance of this question, the expert ends up asking a different set of questions (lines 5-8) that shift the focus to patients' use of the pill. This reformulation is prepared by the description of dietary practice as a burden ('hard to accept', 'a drag', lines 4-5), which is presented as based on patients' own characterization of the diet as difficult 
('What I hea:r here'). Moreover, the yes/no interrogative 'will patients then $\uparrow$ use it' (line 7) is embedded between a preface that establishes the pill as a perfect solution to their highly unpleasant situation (lines 3-6), turning patients into irrational creatures if they would not accept it, and a postscript (lines 7-8) that frames a negative response as reducing the innovators' efforts to a waste of time. Hence, the preference is for a 'yes'.

By withholding an affirmative response (line 9), the patient both resists confirming the presuppositions about the problematic dietary practice and the pill's safety, and about what the expert displays as being at stake here. 'Are we just sitting around here' (lines 7-8) suggests that if the pill is not accepted, it is the innovators who will be negatively affected. So there are orientations to what a rational patient is and a good expert, including experts' and patients' (contested) rights and responsibilities - all of which are crucial for understanding what happens in this interaction.

Crucially, a DP analysis treats whatever kind of norms and rules "not as principles governing human actions, but as a resources that actors might use, or make relevant, in accounting for actions or in arguing about some event" (Edwards 1997: 5, my emphasis). This also applies to the social rules just referred to: notions regarding being a good patient or expert, including their rights and responsibilities, are taken into account in the analysis, but not as something fixed, i.e., as expressed by people's minds or reflecting the world-outthere. They are topicalized, negotiated about and dealt with as part of talk's daily business. Furthermore, DP starts from the ethnomethodological insight (Garfinkel 1967) that accounts of actions are always and at the same time, accounts for actions (Edwards 1997: 8), which explains why participants' 
epistemic and normative work are routinely and inextricably bound up with each other. Significantly enough, norms are often couched in descriptive rather than explicitly normative terms (see the earlier discussion about modal constructions).

It is here where the recent strand of work in CA devoted to epistemics, at times seems to depart from a discursive psychological approach. While it may be a slip of the tongue, Stivers et al. (2011:8) define epistemics as a strand that attempts to "join sociology's interest in knowledge as a norm-governed domain"(my emphasis), where DP would define knowledge as a norm-oriented domain, in which norms function as resources rather than guidelines. The latter corresponds with a 'traditional' CA perspective, in which norms are seen as the 'grid' by reference to which whatever is done will become visible and assessable (Heritage 1984: 117). Remarkably, recent CA work sometimes shows a different view of the matter, in which knowledge plays a role comparable to that in more conventional sociological approaches.

\section{From a causal to a normative model ...and back again?}

The status of intersubjective knowledge is a case-in-point. DP views common knowledge (Edwards 1997: 119) as "inherently indeterminate, or interactionally at issue, rather than treating it as a reservoir of shared factual information which exists prior to, and is built up during, conversations". CA's recent emphasis is on mutual knowledge as "fundamentally involved in the production and ascription of action" (Heritage 2013: 559). More specifically, 'epistemic status' is seen as the central pragmatic resource in determining whether an utterance will be understood as requesting or asserting information. Participants' epistemic status 
refers to the relative access to some knowledge domain of two or more persons at some point in time. Despite the continued focus on the relative and relational nature of that status, there is a simultaneous inclination to resist that, and stress its 'realness'. As Heritage (2013: 558) puts it: "For many domains of knowledge, the epistemic status of the interactants is an easily accessed, unquestionably presupposed, established, real and enduring state of affairs." It is this shared knowledge of participants' epistemic access to some state of affairs that for example permits speakers to produce a statement with declarative syntax (line 5), which is nevertheless heard as a request for information (line 6):

(6) [MidWest 2.4] (Heritage 2012:8)

\begin{tabular}{ll} 
1 DOC: & Are you married? \\
2 & $()$. \\
3 PAT: & No. \\
4 & $()$. \\
5 DOC: $->$ & You're divorced $\left({ }^{\circ}\right.$ cur[rently, $\left.{ }^{\circ}\right)$ \\
6 PAT: & \\
\hline [Mm hm,
\end{tabular}

The argument is that the utterance in line 5 (You're divorced $\left({ }^{\circ}\right.$ currently, $\left.{ }^{\circ}\right)$ ) is treated as an information request (despite its 'informative' syntax), because the interactants share knowledge on their mutual cognitive status or epistemic access. Both participants assume that the utterance concerns information within the patient's epistemic domain and so the doctor is not understood as doing "informing" but as searching for information.

While it may not seem problematic here to assume what participants 'really think' about each other's epistemic status and what this status 'actually is', I would like to argue that it is. First of all, one may wonder what is gained by assuming that participants know each other's epistemic status. In order to 
understand the course of the interaction, it is essential to see that the utterance 'You're divorced ( ${ }^{\circ}$ currently, ${ }^{\circ}$ ' is treated as an information request. For this to observe, we do not need to assume that participants know each other's status, only that they deal with each other as if that is the case. By doing the latter, we keep our eyes open for the fact that not only, the 'sharedness' of knowledge is difficult to determine, but also and more importantly, analytically often too readily assumed.

By refraining from judgments about the realness of participants' epistemic statuses researchers are allowed the space to analyse knowledge as potentially at stake, and 'simply' look at how everyday talk works. That is, as Edwards (2004: 44) puts it, without having to presuppose that talk is a reflection of speakers' and hearers' best mental guesses (the Honest Jo model), or something Machiavellian, on the basis of which interactants are assumed to scheme and plot all day long. Such a practical and dynamic perspective reminds us of the fact that interactants constantly perform work in order to establish 'the obvious'. Following Sacks and Schegloff, Edwards (ibid.) gives the example of how people do recognition rather than simply recognize people, namely by providing some basis for independently knowing the person:

1(a) Holt: 088:1:9:2 (Edwards 2004: 46)

Lesley and Ed have been exchanging remarks on what they have each been doing lately. Ed responds to an inquiry by Lesley into whether he (still?) does 'private teaching'.

$\begin{array}{lll}1 & \text { E: } & \text { (...) I teach at uh:: North Cadb'ry a boy call' } \\ 2 & & \text { Neville Cole? } \\ 3 & \text { L: } & \text { Oh:: [yes:, } \\ 4 & \text { E: } & \text { [over there, (perchance yo[u know im?= } \\ 5 & \text { L: } & \\ 6 & \text { L: } & =\text { No I do:[n't }\end{array}$


Edwards (2004) argues that the orientation to that rule becomes visible in the interaction, for example in line 4, where Ed, despite Lesley's earlier recognition of the boy in line 3, pursues her recognition of the boy's name ((perchance you know im?= ), as if Lesley has not yet been clear enough about it. In order to understand the course of the interaction, not only one does not need to know about participants' assumptions on each other's actual knowledge states, but such knowledge would also be in the way of a clear understanding of what happens here.

'Epistemic status' seems a fruitful concept as long as we do not take it for granted, i.e. not as given, out-there and constraining, but rather as a participants' resource. In that light, the question is whether we need the distinction between epistemic status and epistemic stance. Epistemic stance (Heritage 2012a: 6) is defined as the moment-by-moment expression of knowledge relationships, as managed through the design of turns at talk. Heritage argues that the additional concept of epistemic stance is necessary because epistemic status can be dissembled by persons who deploy epistemic stance to appear more, or less, knowledgeable than they really are (2012b: 33). One may wonder, however, how necessary that distinction is when we let go of the analyst's appreciation of how real a particular knowledge state is and remain focused on analysing these matters as participants' business. Stance is all there is, and even then we need (and should) not assume that this is what participants really think or know. Apart from the fact that it is neither necessary nor analytically fruitful to assume the realness of epistemic status for understanding interaction, there are also grounds of principle for dropping the matter and letting the realness of stance 
and status rest. It dissuades the analyst from reverting to 'ontological gerrymandering' (Woolgar \& Pawluch 1985), that is, shifting between different realities according to the analyst's choice.

It should be noted, however, that some CA analysts are more inclined to 'freeze' knowledge states and deploy the representational model, than others. Raymond (2010: 92), for example, argues that by alternating between questionformats speakers may index (or claim or invoke the salience of) alternative social relations and thus make relevant different response forms. He emphasizes that "the use of a form is not necessarily constrained by nor does it directly reflect what the participants actually know, understand, or think they know "(Raymond 2010: 96, my emphasis). At the other end of the spectrum we find recent work by Stevanovic and Peräkylä (2014: 188), who suggest that social relations are anchored in three orders: the epistemic, deontic and emotional order. The orderliness in people's orientations to these orders is founded on "participants' shared moral and cognitive presuppositions".

The latter comes very close to pursuing causal explanations rather than normative bases for human practices (Edwards 2012), and seems far removed from the original and provoking ideas that Harold Garfinkel and Harvey Sacks once arrived at.

\section{Conclusion}

What happened to, and with, the post-cognitive project in interaction analysis? We have seen how the status of cognition has become a serious area of attention for interaction analysts. While discursive psychologists have grown so fond of CA that they like to see themselves as the true followers of Harvey Sacks's motto 
that one should never worry about how fast people are thinking, or even whether they are thinking, conversation analysts themselves maintain a love-hate relationship with cognition. There is, at least, an inclination to fixate matters and return to the solid ground of 'real' knowledge and 'actual' thinking, whereas discursive psychologists would never want to commit themselves to such an

endeavour. This is not so much an ingrained and ideologically motivated point of view - see Sacks's advice at the beginning of this chapter - but first and foremost a practical way of looking at things: in order to understand what happens in the interaction it does not seem fruitful, counterproductive even, to deploy a causal and realist model of human action. However attractive the model of the 'hydraulic engine' driving sequences of interaction (Heritage 2012b: 49) may sound, there is no compelling reason to embrace it, especially when it is at the expense of the far more dynamic, normative model of human action that still offers us vast and exciting undeveloped sites for research.

\section{References}

Edwards, D. (1997) Discourse and Cognition, London: Sage.

Edwards, D. (2003) Analyzing racial discourse: the discursive psychology of mind-world relationships, in H. van den Berg, M. Wetherell, \& H. Houtkoop-Steenstra (Eds.), Analyzing Race Talk: Multidisciplinary Approaches to the Interview (pp. 31-48). Cambridge, UK: Cambridge University Press. 
Edwards, D. (2004) 'Shared knowledge as a performative category in conversation', Rivista di Psicololinguistica Applicata, 4: 41-53.

Edwards, D. (2006a) 'Discourse, cognition and social practices: the rich surface of language and social interaction', Discourse Studies, 8: 41-49.

Edwards, D. (2006b) 'Facts, norms and dispositions: practical uses of the modal verb would in police interrogations', Discourse Studies, 8: 475-501.

Edwards, D. (2007) 'Managing subjectivity in talk', in A. Hepburn \& S. Wiggins (Eds.), Discursive Research in Practice: New Approaches to Psychology and Interaction (pp. 31-49), Cambridge: Cambridge University Press.

Edwards, D. (2012) 'Discursive and scientific psychology', British Journal of Social Psychology, 51: 425-435.

Edwards, D., Ashmore, M., and Potter, J., (1995) 'Death and furniture: The rhetoric, politics and theology of bottom line arguments against relativism', History of the Human Sciences, 8: 25-49.

Edwards, D., and Potter, J. (1992) Discursive Psychology, London, UK: Sage. Garfinkel, H. (1967) Studies in Ethnomethodology, Englewood Cliffs, NJ: PrenticeHall.

Heritage, J.C. (1984) Garfinkel and Ethnomethodology, Cambridge: Polity.

Heritage, J. (2012a) 'Epistemics in action: Action formation and territories of knowledge', Research on Language and Social Interaction, 45: 1-29.

Heritage, J. (2012b) 'The epistemic engine: Sequence organization and territories of knowledge', Research on Language and Social Interaction, 45: 30-52.

Heritage, J. (2013) 'Action formation and its epistemic (and other) backgrounds', Discourse Studies, 15: 551-578. 
Potter, J. (1996) Representing Reality: Discourse, Rhetoric and Social Construction. London: Sage.

Potter, J. (2006) ‘Conversation and cognition', Discourse Studies, 8: 131-140.

Raymond, G. (2010) 'Grammar and social relations: alternative forms of Yes/Notype initiating actions in health visitor interactions', in A. Freed and S. Ehrlich (Eds.), "Why Do You Ask?” The Function of Questions in Institutional Discourse (pp. 87-107). Oxford: Oxford University Press.

Sacks, H. (1992) Lectures on Conversation, Vols I and II, edited by G. Jefferson. Oxford: Blackwell.

Sneijder, P. and te Molder, H. (2005) 'Moral logic and logical morality: Attributions of responsibility and blame in online discourse on veganism', Discourse \& Society, 16: 675-696.

$\underline{\text { Stevanovic, M. \& Peräkylä, A. (2014) 'Three orders in the organization of human }}$ action and social relations: On the interface between knowledge, power, and emotion in interaction', Language in Society, 43: 185-207.

Stivers, T. , Mondada, L., and Steensig, J. (2011) ‘Knowledge, morality and affiliation in social interaction', in Stivers, T. , Mondada, L., \& Steensig, J. (Eds.), The Morality of Knowledge in Conversation (pp. 3-24). Cambridge: Cambridge University Press.

te Molder, H. and Potter, J. (Eds.) (2005) Conversation and Cognition, Cambridge: Cambridge University Press.

Veen, M., te Molder, H., Gremmen, B. and van Woerkum, C. (2012) 'Competing agendas in upstream engagement meetings between celiac disease experts and patients', Science Communication, 34: 460-486. 
Wiggins, S. (2014) 'Adult and child use of love, like, don't like and hate during family mealtimes : subjective category assessments as food preference talk', Appetite, 80: 7-15.

Woolgar, S. and Pawluch, D. ( 1985) 'Ontological gerrymandering', Social Problems, 32: 214-27. 